\title{
MODOS DE REGULAÇÃO INSTITUCIONAL DA INVESTIGAÇÃO EDUCACIONAL: O CASO DO INSTITUTO DE INOVAÇÃO EDUCACIONAL*
}

\author{
SOFIA VISEU ${ }^{* *}$
}

\begin{abstract}
RESUMO: Este artigo apresenta um estudo empírico ilustrativo da evolução dos modos de regulação das políticas públicas de ciência, atualmente marcadas pelo progressivo aumento do controlo externo da atividade científica. Centrando-se na ação de um instituto público que operou em Portugal entre 1989 e 2001, o estudo analisa modos de regulação institucional, i.e., como o Estado procurou orientar e influenciar a investigação educacional através de uma estrutura vocacionada para a produção de conhecimento útil à decisão política. Para além destes modos de regulação, o estudo identificou outros, resultantes da forma como essas orientações foram apropriadas pelos investigadores e reinterpretadas pelos decisores políticos, dando conta da complexidade das políticas públicas de ciência.
\end{abstract}

Palavras-chave: Pesquisa. Regulação. Instituto de Inovação Educacional.

\section{EDUCATIONAL RESEARCH INSTITUTIONAL MODES OF REGULATION: THE CASE OF THE INSTITUTE FOR EDUCATIONAL INNOVATION}

\begin{abstract}
This paper presents an illustrative empirical study on the evolution of public policies regulation modes concerning Science, as scientific activity is currently marked by a gradual intensification of external control. Focusing on the action of a public institute that operated in Portugal between 1989 and 2001, the study examines how the State sought to guide and influence educational research, in particular by creating a framework guided towards the production of useful knowledge for policy-making. In addition to these modes of institutional regulation, the study has also identified other modes of regulation, arising from the way researchers have appropriated these guidelines and policy makers have re-interpreted them, accounting for the complexity of public policies for Science.
\end{abstract}

Key words: Research. Regulation. Institute for Educational Innovation.

* A autora agradece os contributos do professor João Barroso.

* Unidade de Investigação e Desenvolvimento em Educação e Formação, Instituto de Educação da Universidade de Lisboa. Lisboa - Portugal.

Contato com a autora: <sviseu@ie.ulisboa.pt> 


\section{LES MODES DE REGULATION INSTITUTIONNELLE DE LA RECHERCHE SColaire: Le CAS de L'INSTitut d'InNovation Pedagogique}

RÉSUMÉ: Cet article présente une étude empirique illustrant l'évolution des modes de régulation des politiques publiques sur les sciences, actuellement marqués par l'augmentation progressive du contrôle externe de l'activité scientifique. En utilisant l'action d'un institut public qui opérait au Portugal entre 1989 et 2001, l'étude examine la façon dont l'État cherchait à orienter et à influencer la recherche en éducation, en particulier à travers la création d'un cadre pour la production de connaissances utiles pour la prise de décision politique. Au-delà de ces modes de régulation institutionnelles, l'étude a également identifiée d'autres modes de régulation, résultant de la façon dont les chercheurs les ont prises et comment les décideurs politiques se sont réappropriés de ces orientations, en tenant compte de la complexité des politiques publiques sur les sciences.

Mots-clés: Recherche. Régulation. Institut pour l'innovation pédagogique.

\section{Introdução}

s atuais políticas públicas de ciência na maioria dos países ocidentais e nos
países associados às economias emergentes caracterizam-se pela aposta e
reforço no designado performance-based research funding. Este modelo privilegia, entre outras medidas, o financiamento de base competitiva, atendendo a indicadores de desempenho, tais como a publicação em revistas científicas com impacto de citação ou o número de estudantes de pós-graduação (ABRAMO; CICERO; D'ANGELO, 2011). Estas características configuram uma evolução dos modos de regulação que tendem a acentuar a avaliação e controlo externo da atividade científica (BOURDIEU, 2004).

Atendendo às exigências que colocam aos investigadores, estas orientações têm provocado alguma contestação em diversos fóruns científicos, especialmente no domínio das ciências sociais (BROWN; SCHUBERT, 2000). Para Ball (1995), elas representam um constrangimento à autonomia do trabalho científico, atendendo ao apelo, ainda que implícito, de uma maior aproximação das agendas científicas às agendas políticas. Desjardins e Rubenson (2009) referem que estas tendências fazem sentir-se de modo particularmente acentuado na investigação educacional, considerando a sua fragmentação institucional. Num registo mais crítico, Lima (2010) denuncia que estas medidas reforçam o caráter instrumental que é frequentemente atribuído à investigação educacional, aproximando-a do estatuto de "tecnociência" (LIMA, 2010, p. 67). Considerando a polémica gerada e a tensão vivida a propósito dos novos modos de regulação, Ozga, Seddon e Popkewitz (2006) defendem que a investigação educacional se constitui como um terreno propício para estudo das opções de política de ciência. 
O cenário descrito justifica este texto onde se apresenta um estudo empíri$\mathrm{Co}^{1}$ que pretende ilustrar modos de regulação institucional, i.e., o modo como as autoridades governamentais tentam orientar e influenciar a produção científica. $\mathrm{O}$ estudo incidiu sobre a ação regulatória de uma agência pública criada em 1989, em Portugal, e que operou até 2002 sob a tutela do Ministério da Educação, o Instituto de Inovação Educacional (IIE²), tomando-o como um caso profícuo para a análise de modos de regulação institucional da investigação educacional.

O estudo incidiu sobre um extenso corpus documental, incluindo legislação, planos e relatórios de atividade, editais e regulamentos de concursos de apoio financeiro a projetos de investigação e publicações diversas do Instituto. Foram ainda realizadas quatro entrevistas semiestruturadas (COHEN; MANION, 1994) a antigos dirigentes do Instituto (identificados como E1, E2, E3 e E4), com o objetivo conhecer as suas representações sobre a ação dessa agência na orientação da investigação educacional.

Apesar de se centrar na regulação institucional, o estudo não ignora que o modo como as autoridades governamentais tentam influenciar a produção científica não traduz a realidade social (TERSSAC, 2003). Nesse sentido, filia-se numa tradição de investigação que, acentuando a imprevisibilidade da ação pública, procura descrever e captar a complexidade dos processos que compõem as políticas públicas (LASCOUMES; LE GALÈS, 2007). Assim, embora o estudo esteja focado na ação de uma estrutura de regulação institucional, os dados relevaram outros modos de regulação resultantes da ação dos atores sociais que, atendendo aos seus interesses e estratégias, (re)ajustam as regras nos seus contextos sociais, designadamente investigadores e decisores políticos (BARROSO, 2006).

O texto está organizado em três secções. Na primeira secção, far-se-á uma nota sobre a evolução da regulação das políticas públicas de ciência, procurando dar conta do progressivo reforço do controlo externo da atividade científica. Na segunda secção, apresentar-se-ão os modos de regulação institucional da investigação educacional identificados a partir do estudo empírico. Na terceira secção, dar-se-á conta de outros modos de regulação, que dizem respeito à forma como essas orientações foram apropriadas pelos investigadores e reinterpretadas pelos decisores políticos. $\mathrm{O}$ artigo termina com algumas considerações finais.

\section{Evolução da regulação das políticas públicas de ciência}

Na generalidade dos países ocidentais, a emergência das políticas públicas de ciência no século XX baseou-se num modelo segundo o qual as autoridades públicas forneceriam os recursos necessários à comunidade científica e esta devolveria aos 
decisores políticos conhecimento que lhes permitisse melhores e mais fundamentadas opções (HESSELS; VAN LENTE, 2010). Estabeleceram-se, assim, princípios de autorregulação nos sistemas científicos, valorizando-se normas internas em detrimento de outros processos de regulação estatal (GONÇALVES, 1996).

Atualmente, e apesar de especificidades nacionais e temporais, as políticas públicas de ciência caracterizam-se pela progressiva substituição dos princípios de autorregulação por uma crescente introdução de mecanismos de controlo externo da atividade científica (VISEU, 2012). Note-se que esta tendência remonta a um processo mais amplo de reconfiguração do papel do Estado, presente em múltiplos setores das políticas públicas, que apela à introdução de lógicas de mercado nos serviços públicos, onde se inclui a criação de dispositivos de avaliação e de prestação de contas (AFONSO, 2003). Neste processo, os tradicionais modos de regulação baseados na autoridade formal, normativa e legisladora, vão sendo substituídos, progressivamente, por outros modos de regulação, também designados por pós-burocráticos, que assentam em políticas constitutivas, tendencialmente mais indiretas e de controlo da ação a posteriori (HASSENTEUFEL, 2008). Por exemplo, a avaliação, os concursos e prémios, as contratualizações e as boas práticas surgem como modos preferenciais de orientação da ação pública (MAROY; DEMAILLY, 2004).

Em simultâneo, a ciência ganha um crescente protagonismo na regulação das políticas públicas. Por um lado, centrando-se nos resultados da ação, os novos modos de regulação apelam à produção de um conhecimento especializado e avaliativo, vocacionado para a construção de indicadores, escalas ou visando comparações internacionais (DEMAILLY, 2011). Assim, privilegiando modos de regulação baseados em resultados de processos de avaliação, o conhecimento atua como instrumento de regulação, na medida em que a sua produção e disseminação é utilizada para a orientação da ação pública (FREEMAN; SMITH-MERRY, STURDY, 2012). Por outro lado, considerando a dificuldade de afirmação das autoridades políticas com base no estatuto, o conhecimento, designadamente o conhecimento científico, vem sendo utilizado para legitimar as escolhas políticas (HANBERGER, 2003). Estando as políticas públicas de educação "explicitamente orientadas para o conhecimento" (MANGEZ, 2011, p. 196), esse protagonismo torna-se particularmente sensível e acentua o caráter instrumental que é frequentemente atribuído à investigação educacional. Foi no contexto desta evolução que selecionei o estudo de uma agência estatal para ilustrar modos de regulação institucional da investigação educacional.

\section{A criação de uma estrutura de regulação institucional}

Num texto de 1992, Popkewitz e Pereyra davam conta da tendência seguida em vários países europeus que, empenhados na implementação de reformas 
educativas durante a década de 1980, apostaram em "novas entidades e modelos de certificação e o estabelecimento de instituições de investigação [...] para orientar o ensino" (POPKEWITZ; PEREYRA, 1992, p. 12).

Neste contexto, a criação de uma agência governamental no final da década de 1980, sob a tutela do Ministério da Educação em Portugal, com competências na "coordenação da investigação" (Decreto-Lei n. 3/87, de 3 de janeiro), não se tratou propriamente de uma originalidade nacional. Sobre a criação do Instituto importa reter dois aspetos particularmente relevantes para caracterizar os modos de regulação institucional da investigação educacional.

O primeiro refere-se à produção e mobilização de conhecimento numa lógica de legitimação da decisão política. De facto, o Instituto foi concebido no quadro da aplicação de um movimento de reforma educativa que decorreu da aprovação, em 1986, da primeira Lei de Bases do Sistema Educativo em Portugal. ${ }^{3}$ A reforma educativa então em curso ambicionava solucionar os problemas do sistema educativo, marcado pelo insucesso escolar, a falta de formação de professores, a desadequada gestão e a desatualização curricular (PACHECO, 1991; FORMOSINHO, 2000). Note-se, contudo, que, tal como demonstrado por Barroso (2001), a reforma foi concebida num modelo normativo - dedutivo centralizador em que, grosso modo, o Estado concebe e as escolas aplicam. Este modelo obrigava, por consequência, a uma maior sofisticação dos instrumentos de conhecimento sobre o sistema educativo, nomeadamente sobre os aspetos relacionados com as temáticas da reforma: a inovação educacional, o desenvolvimento curricular e organizacional do sistema educativo. Num registo crítico, um dos entrevistados sublinhou que a ação do Instituto passava, sobretudo, pela persuasão das escolas para aderirem ao movimento da reforma educativa: "O IIE [...] é claramente o braço armado da reforma educativa. [...] Fez-se a reforma e agora é preciso uma espécie de Cavalo de Troia que faça com que as escolas aceitem e engulam estas coisas e façam isto" (E1).

Compreende-se, assim, a criação de uma agência governamental vocacionada para a promoção e produção de conhecimento que sustentasse o movimento de reforma educativa, no quadro de um país de tradição centralizadora do Estado como é o caso de Portugal (BARROSO, 2001).

O segundo aspeto relevante a propósito da criação do Instituto e dos seus modos de regulação refere-se à adoção de um papel ativo por parte do Estado na produção de conhecimento considerado relevante para as políticas educativas. A comprová-lo está a primeira lei orgânica do Instituto que o definia como autor de "propostas de inovação":

A reforma do sistema educativo em curso propõe-se a reestruturar globalmente o sistema [...]. Não pode haver inovação educacional consistente sem o suporte da investigação 
científico-educacional. O Instituto de Inovação Educacional foi criado para responder de forma integrada [a esses] objetivos [...]. Compete-lhe, de acordo com a política educativa definida, desenvolver propostas de inovação nas várias áreas do sistema educativo. (Decreto-Lei n. 435/89, de 18 de dezembro)

De resto, o primeiro presidente do Instituto sublinhava que a criação dessa agência significava a "adoção de uma política de promoção e incremento da investigação em educação" (PATRÍCIO, 1989, p. 394) por parte do Estado, concebendo o IIE como o "organismo central de coordenação de investigação e desenvolvimento no âmbito do Ministério da Educação" (idem, p. 401).

Em paralelo com a tentativa em nortear a investigação educacional a partir de orientações provenientes da administração central, é interessante observar que a Lei de Bases elegia as instituições de ensino superior como os lugares privilegiados de produção da investigação em educação:

A investigação em educação destina-se a avaliar e interpretar cientificamente a atividade desenvolvida no sistema educativo, devendo ser incentivada, nomeadamente nas instituições de ensino superior que possuam centros ou departamentos de ciências da educação. (Artigo 50ํㅡㅁa Lei n. 46/86, de 14 de outubro).

Constata-se assim, dentro do próprio Estado, a coexistência de duas conceções sobre as modalidades de regular institucionalmente a investigação: uma primeira comprometida na produção de conhecimento por parte de uma agência pública com competências na investigação educacional, e uma outra, que apostava no incentivo à investigação educacional produzida na academia.

\section{Para a produção de conhecimento útil para a decisão política}

A tentativa de controlo de uma agenda científica constitui, segundo Johanningmeier e Richardson (2008), uma característica comum na regulação por parte do Estado. Este modo de regulação compreende-se pela adoção de uma perspetiva de políticas baseadas no conhecimento, knowledge-based policy, que esteve enraizada na criação dos sistemas científicos - que justificou, em parte, o sistema de autorregulação supramencionado - e continua a desempenhar um papel central nas políticas públicas (VAN ZANTEN, 2006).

Sobretudo a partir da década de 1990, os dados relevaram que, progressivamente, o Instituto visou influenciar a agenda de investigação para a produção de um conhecimento prático, útil e com temáticas consonantes com as prioridades das políticas educativas. Esta ideia consta de vários documentos produzidos ao longo da sua existência, conforme atestam os seguintes excertos relativos à definição de objetivos para a ação do instituto: "influenciar a agenda dos centros de investigação, 
direcionando-a para problemas com que se defrontam as nossas escolas" (IIE, 1996, p. 10); "influenciar a agenda da investigação no sentido de maior relevância para a inovação" (IIE, 1999, p. 1); "promover investigações úteis - pelo assunto e pela oportunidade temporal - aos decisores educativos", bem como "exigir produtos e recomendações operacionais em resultado dessas investigações" (IIE, 2000, p. 12). A produção de conhecimento útil à decisão política foi também reconhecida por dois entrevistados como um objetivo do instituto:

Era ter [...] uma instituição que se tornasse imprescindível ao desenvolvimento o sistema educativo, fazendo a ponte com [...] as universidades e com o poder. O conhecimento fluía e [...] tornariam o IIE indispensável ao poder. (E2)

Havia muito pouca investigação útil para o decisor nos centros universitários [...]. Introduziam-se as medidas e[íamos] fazer uma investigação para ver como as coisas [estavam] a correr. Também para legitimar [a decisão política]. (E4)

Visando a concretização deste objetivo, foram desencadeadas duas medidas: (i) a produção de investigação no instituto; (ii) o apoio financeiro de base competitiva a projetos de investigação conduzidos, nomeadamente, por instituições de ensino superior. Estas medidas traduzem a coexistência das duas visões sobre os modos de concretização da missão do Instituto descritas anteriormente.

\section{A produção de investigação no Instituto}

$\mathrm{Na}$ administração dos sistemas educativos tem vindo a acentuar-se uma tendência para uma progressiva alteração da sua tecnoestrutura, "tendo em vista a criação de um saber 'próprio' especializado, ao nível dos estudos de avaliação, da realização de comparações internacionais, dos observatórios de políticas (ou de práticas)" (BARROSO; CARVALHO, 2011, p. 13). A este propósito, alguns autores referem-se a uma ciência da governamentalização para sublinhar a existência de conhecimentos produzidos no interior do próprio Estado ou em forte interação com o poder (VAN ZANTEN, 2006).

Nesta perspetiva, percebe-se a opção pela aposta assinalável na produção de conhecimento por parte dos técnicos que trabalhavam no Instituto para dar resposta a "solicitações da tutela ou outros organismos do Ministério da Educação": "Ao longo de 2001, o IIE correspondeu às prioridades do sistema, designadamente no que diz respeito às mudanças curriculares, fazendo reverter para essas os projetos [de investigação] em curso no IIE" (Relatório de atividades do IIE de 2001, p. 3).

Um indicador desta produção pode ser encontrado a partir da análise da autoria dos artigos de um periódico editado pelo Instituto, a Revista Inovação. Ao longo dos 14 anos da sua existência, $12,3 \%$ dos artigos publicados foram assinados por autores 
pertencentes ao Instituto. Este valor pode ser considerado relevante, atendendo a que só foi ultrapassado pela percentagem de autorias de investigadores pertencentes a instituições de ensino superior (VISEU, 2012). Este dado concorre para a caracterização do Instituto como um "centro de investigação em educação", tal como foi descrito por um dos seus presidentes, para sublinhar o papel desta agência em produzir investigação e inscrever problemas na agenda científica (CAMPOS, 1995, p. 6).

\section{O apoio financeiro de base competitiva a projetos de investigação}

Acompanhando uma tendência presente na generalidade das políticas públicas de ciência das últimas décadas, que apostam na introdução de mecanismos de financiamento de base competitiva, o IIE promoveu concursos de apoio a projetos de investigação baseados em convites à apresentação de candidaturas avaliadas através de peer review. Estes concursos apoiavam projetos "centrados em problemas das escolas e [...] com o seu envolvimento" (IIE, 1999, p. 1), com um "mínimo de relevância para a solução dos problemas da educação", ou visando o desenvolvimento de "métodos e materiais pedagógicos inovadores" (IIE, 1995, p. 51). Formulados nestes termos, os concursos evidenciaram uma tentativa de influenciar a agenda científica, dando particular relevância à produção de conhecimento útil à decisão política.

A análise dos regulamentos das várias edições destes concursos ao longo do tempo permitiu verificar um progressivo estreitamento dos critérios de avaliação e maior especificação quanto às características preferenciais dos projetos a apoiar, incluindo as temáticas (inovação e qualidade) e os destinatários (decisores políticos e "práticos"). De facto, o primeiro concurso nacional de investigação em educação, em 1989, estabelecia os seguintes objetivos:

a) Fomentar a investigação em educação;

b) Promover a realização de investigações em educação em áreas de necessidade prioritária do sistema educação;

c) Proporcionar apoio financeiro a projetos de investigação que contribuíssem para a consecução dos objetivos anteriormente referidos". (Regulamento do Concurso Nacional de Projetos de Investigação em Educação)

Seis anos mais tarde, em 1995, o regulamento do apoio financeiro aos projetos de investigação passou a comtemplar os seguintes critérios para a apreciação das candidaturas:

- $\quad$ A relevância do conhecimento a produzir e/ou dos métodos e materiais pedagógicos a desenvolver para a solução de problemas educativos; 
- $\quad$ A qualidade científica e pedagógica do projeto;

- O curriculum vitae científico e pedagógico do coordenador;

- Os benefícios para o desenvolvimento do projeto, resultantes da eventual colaboração de centros de investigação ou de associações. (Regulamento do Apoio Financeiro aos Projetos de Investigação)

Como consequência, ocorreu um cenário de seleção mais afinado para a atribuição de financiamento: nesse ano foram apresentadas 117 candidaturas, das quais apenas 41 foram consideradas para efeitos de financiamento, o que equivale a 35\% do total das candidaturas apresentadas (RELATÓRIO DE EXECUÇÃO DO SIQE, 1995).

Em 2001, o regulamento incluiu critérios de avaliação mais sofisticados, nomeadamente, a "adequação do projeto à natureza do concurso e das respetivas características investigativas", bem como a "qualidade científica do projeto", incluindo descritivos sobre o "rigor, consistência e adequação da explicitação dos fundamentos teóricos, da definição do objeto, da proposta de metodologia e técnicas, dos resultados e produtos esperados" e a "qualidade pedagógica (pressupostos e impacto previsto, articulação com os contextos e mobilização dos atores)" (Regulamento específico anexo ao Despacho n. 8/IIE/2001).

Este processo de refinamento dos critérios para a avaliação dos projetos a concurso indiciou um esforço para uma maior orientação da investigação a financiar, tal como relataram os entrevistados: "Os regulamentos passaram a contemplar determinados critérios. [A intenção passou a ser] não contemplar muitos [projetos em cada concurso], mas alguns de acordo com as necessidades" (E3).

Os dados revelaram um alcance razoável da tentativa de produção de conhecimento científico que incidisse sobre as temáticas consideradas pertinentes para a decisão política ou para a orientação das práticas pedagógicas. Uma análise realizada por Nóvoa (1996) aos projetos apoiados no âmbito dos concursos nacionais de investigação em educação, entre 1989 e 1994, mostrou a prevalência de temáticas relacionadas com a formação de professores, o desenvolvimento curricular e a inovação. Segundo o mesmo autor, estes dados justificam-se "pelo período de reforma educativa que se viveu durante o período em análise" (NÓVOA, 1996, p. 101). No mesmo sentido, o levantamento conduzido por Silva (2006, p. 154) sobre os projetos de investigação apoiados entre 1996 e 2001 revelou mais "continuidades do que dissonâncias" entre as temáticas dos projetos e a publicação de normativos legais que regulamentavam a ação do sistema educativo; veja-se, por exemplo, a incidência dos projetos apoiados financeiramente em 2001 nas temáticas da gestão flexível do currículo, da educação para a cidadania e da reorganização curricular, coincidindo com 
a atualização de orientações normativas nestas matérias (Decretos-Leis n. 6/2001 e n. 7/2001, de 18 de janeiro).

\section{Outros modos de regulação}

Paralelamente com o desenvolvimento dos modos de regulação institucional identificados, o estudo relevou a coexistência de outros modos de regulação da investigação educacional, comprovando que a regulação não se faz automaticamente, mas antes através de um "processo de alinhamento entre diferentes atores, sejam reguladores ou regulados" (FREEMAN et al., 2012, p. 14).

No domínio dos "regulados", destaca-se a tentativa dos investigadores em manter margens de autonomia que lhes permitissem alinhar os critérios estabelecidos nos concursos de apoio financeiro com as suas agendas de investigação. Nesse sentido, os entrevistados deram conta da dificuldade em orientar os investigadores para uma maior colaboração com os "práticos" e que produzissem "conhecimento útil": "[Os investigadores] não cumprem os critérios mais objetivos [dos concursos para apoio financeiro à investigação]" (E4); "Íamos lançando alguns critérios de seleção que talvez conduzissem noutro sentido [...] mas nem sempre era possível" (E3). De facto, o primeiro regulamento do concurso nacional de projetos de investigação excluía o apoio financeiro para "provas de doutoramento, mestrado, aptidão pedagógica ou qualquer prova de progressão na carreira" (Regulamento do concurso nacional de projetos de investigação em educação de 1989, p. 4). Porém, o estudo conduzido por Nóvoa (1996), já citado, relevou que, durante os primeiros concursos, houve uma tendência para que este financiamento fosse canalizado para o apoio de realização de provas académicas.

No domínio dos "reguladores", refira-se que, apesar das intenções em orientar a investigação educacional produzida, designadamente, na academia, o financiamento disponibilizado pelos concursos de projetos de investigação não teria sido suficiente para alterar substantivamente a produção científica, sendo frequentemente dedicadas a colmatar insuficiências nas infraestruturas ou nas condições de trabalho (NÓVOA, op. cit.). De resto, um dos presidentes do Instituto reconhecia que o "financiamento global concedido anualmente [...] não [era] muito elevado" (CAMPOS, 1993, p. 22). A comprová-lo está a distribuição de verbas no âmbito do "sistema de incentivo à qualidade da educação", um programa de apoio financeiro que incluía, para além da investigação, a inovação e a disseminação de inovações e investigações: entre 1995 e 1998, o montante das verbas destinadas ao apoio à investigação situou-se entre os 13,9\% e os 17,3\% do total das verbas atribuídas através do programa. ${ }^{4}$ 
Ainda no domínio dos "reguladores", refira-se o questionamento, dentro do próprio Ministério da Educação, sobre o efetivo contributo da investigação promovida sob os auspícios do IIE para a decisão política, sendo o episódio da extinção desta agência importante indicador desse fenómeno. Em 2002, tomou posse um novo governo que definiu uma reorganização na administração central do Estado, justificada pela necessidade de consolidação orçamental (Lei n. 109-B/2001, de 27 de dezembro) e determinou a reestruturação, fusão e extinção de vários organismos públicos, entre eles o IIE. Este fenómeno foi interpretado por alguns dos entrevistados como uma medida que permitia, no imediato, reduzir despesas da administração central, considerando o IIE um "alvo fácil" por não criar "um vazio [...] [no] funcionamento do Ministério"(E3).

Contudo, os dados sugerem que para esta decisão podem ter pesado fatores que não se limitariam à questão orçamental, entre os quais a prevalência de "visão 'racionalista' acerca das relações entre conhecimento e política" (CARVALHO, 2011, p. 31) que pairou sobre a ação do instituto. ${ }^{5}$ Para ilustrar esta ideia, evoca-se um estudo realizado por Barroso (2010), para recuperar as palavras tecidas pelo ministro da Educação em funções à data da extinção do Instituto que, "um dia, solicitou que lhe enviassem uma coleção de todos os livros editados pelo Instituto de Inovação Educacional":

Apareceram-me três caixotes de livros e eu durante o fim de semana levei aquilo para casa e comecei a tirar do caixote, um a um, e a dar uma vista de olhos [...]. Daqueles três caixotes eu tirei três ou quatro livros como deve ser, ou seja, daquilo que era "importante". Segundo o ministro, o problema não tinha a ver "com a qualidade científica ou académica", mas sim com os contributos que aquela literatura dava à decisão política: "o que é que isto me vai esclarecer, qual é o contributo e a relevância que isto tem para eu poder pensar as coisas? Devo dizer que apanhei uma desilusão enorme". (BARROSO, op. cit., p. 41)

No mesmo sentido, um dos entrevistados referiu-se a uma "certa frustração [...] que [...] tínhamos que combater: '[...] Para que é que isto serve? O que é que se pode dizer daqui aos professores?"' (E4). Esta "desilusão enorme" e "frustração" por parte dos "reguladores"/ decisores políticos compreende-se no quadro da existência de uma expetativa em colocar o conhecimento ao serviço da política educativa, através de um processo de transferência linear entre ambos, e resulta de uma sobrevalorização do conhecimento científico (veja-se, por exemplo, SOUSA SANTOS, 1988; FEYERABEND, 1993).

As estratégias dos investigadores, a disponibilização de mais financiamento, assim como a "frustração" dos decisores políticos constituem exemplos de outros modos de regulação, considerando que se traduzem na maneira como os atores se apropriaram e reinterpretaram as intenções iniciais que motivaram a criação de uma estrutura de regulação institucional da investigação educacional. 


\section{Considerações finais}

O estudo da ação de uma agência pública concebida para coordenar e orientar a investigação educacional revelou modos de regulação institucional que consistiram na criação de uma estrutura, na dependência da administração central do Estado, com competências na investigação educacional, visando a promoção de conhecimento útil para a decisão política. A fórmula encontrada para estes modos de regulação sugere três pontos de reflexão.

Em primeiro lugar, na sua conceção, a ação do IIE para orientar a investigação educacional definiu-se a partir de instrumentos de regulação institucionais tradicionais, que apelam a normas e legislação, e pela definição desta agência como o "organismo central" responsável pela "coordenação da investigação" no Ministério da Educação. A opção em influenciar a agenda científica através de um pendor normativo e centralizador poderia ter-se afirmado, predominantemente, no estabelecimento de contratos e de encomendas de investigação ou na realização de investigação nos próprios serviços do Ministério. Contudo, progressivamente, houve uma crescente aposta na promoção de concursos de financiamento de base competitiva a projetos de investigação realizados noutras instituições. Esta mudança traduziu-se na produção de novos modos de regulação institucional, com características tendencialmente pós-burocráticas, pelo facto de privilegiarem o controlo da atividade científica a posteriori, através do recurso à avaliação de candidaturas de projetos para efeitos de financiamento. Nesse sentido, a análise dos dispositivos de orientação da investigação desencadeados é exemplar para dar conta da evolução dos modos de regulação das políticas públicas de ciência nas últimas décadas, comum noutros setores das políticas públicas, e que se referem à gradual substituição de tradicionais modos de regulação por outros, designados por pós-burocráticos (STEINER-KHAMSI, 2008; KNOW AND POL, 2008).

Em segundo lugar, os dados deram conta da complexidade que reveste as relações entre conhecimento e decisão política, que se pautam frequentemente por um carácter errático e, por vezes, oportunista (AUTÈS, 2007). É certo que houve uma determinada convergência temática entre os projetos apoiados e a agenda política, o que dá conta de uma bem-sucedida tentativa de influenciar a produção científica. Todavia, os dispositivos criados para condicionar a agenda científica foram interpretados pelos investigadores que, procurando manter as suas margens de autonomia, contornaram e adequaram os critérios de apoio à investigação às suas agendas e interesses, caracterizando-se, assim, como "atores estratégicos" (CROZIER; FRIEDBERG, 1977). Paralelamente, os dados deram conta de uma certa frustração ou desilusão por parte dos decisores políticos em relação à utilidade da produção científica resultante da ação do Instituto para a decisão política. Estes dados mostram 
como as relações entre conhecimento e decisão política são pouco compreensíveis num quadro interpretativo de um processo de transferência linear entre ambos.

Finamente, em terceiro lugar, o recurso ao conceito de regulação permitiu identificar, para além dos modos de regulação institucional, outros modos de regulação, e que traduzem o que Reynaud (2003) designou de regulação autónoma, i.e., o modo como os atores sociais recebem e se (re)ajustam aos mecanismos e aos conteúdos de sentido que caracterizam a regulação de controlo, de acordo com os seus interesses. Estes fenómenos de regulação autónoma estão, desde logo, presentes no sentido estratégico da ação dos investigadores. Mas também estão, necessariamente, presentes dentro da própria estrutura estatal concebida para orientar e controlar da investigação, o que foi possível constatar pela coexistência de duas conceções sobre os modos preferenciais de influenciar a agenda científica: a produção de conhecimento por parte de uma agência pública com competências na investigação educacional e o incentivo à investigação educacional produzida na academia. Este dado concorre para a descrição do Estado como um ator compósito, onde coabitam diversas estratégias, por vezes de natureza contrária (LASCOUMES; LE GALÈS, 2007).

Em síntese, a variedade de estratégias e interesses de decisores políticos e de investigadores produziu efeitos não previstos de acumulação e tornou os resultados da ação do Instituto imprevisíveis. Por isso, para além de modos de regulação institucional, dos efeitos ou injunções na investigação educacional, importa sublinhar que o estudo forneceu dados relativos à interceção de modos de regulação institucional com fenómenos de regulação autónoma. Num quadro de crescimento e reconfiguração dos modos de regulação da investigação, e da polémica a eles associada, parece demonstrada a pertinência da análise das políticas numa perspetiva de ação pública para captar o seu carácter híbrido, complexo e multirregulado (COMMAILLE, 2006).

\section{Notas}

1. O estudo integra parte de uma pesquisa de doutorado apresentada à Universidade de Lisboa em 2012 e recebeu o apoio da Fundação para a Ciência e a Tecnologia (SFRH/BD/60714/2009).

2. Para além da sua ação no âmbito do apoio à inovação e investigação educacional, destaco também as seguintes atividades do IIE: a) no domínio da difusão de conhecimento, a publicação da Revista Noesis, a Revista Inovação, o Vídeo jornal Clip, revista IIE em Notícia, o jornal escolar eletrónico Teia; a organização de um fórum de projetos de inovação e investigação; o desenvolvimento de uma linha editorial própria que, entre coleções e coedições, publicou 303 livros entre 1989 e 2002; b) a cooperação com instituições e projetos internacionais; c) a organização de bases de dados sobre projetos nacionais de investigação educacional e de literatura cinzenta em educação, entre outras.

3. A Lei de Bases do Sistema Educativo equivale, no essencial, à Lei de Diretrizes e Bases da Educação.

4. Não tendo sido possível localizar e identificar uma fonte primária relativa às candidaturas e projetos aprovados, socorri-me da informação já existente e tratada, designadamente, em Nóvoa (1996) e Silva (2006). 
5. Os entrevistados deram conta de outros fatores que, atuando em conjunto, determinaram o encerramento do Instituto: a existência de pressões por parte dos investigadores para acentuar a autonomia científica das suas agendas de investigação, por considerarem que "tudo o que era investigação devia ser feito na universidade e não [em] serviços do Estado" e pressões de outros “departamentos do Ministério [que] achavam que o IIE tinha condições mais privilegiadas, mais favoráveis" (E4).

\section{Referências}

ABRAMO, G.; CICERO, T.; D'ANGELO, C. The dangers of performance-based research funding in non-competitive higher education systems. Scientometrics, Amsterdam, v. 87, n. 3, p. 641-654, jun. 2011. Disponível em: < http://link.springer.com/ article/10.1007/s11192-011-0355-4/fulltext.html > Acesso em: 25 maio 2013.

AFONSO, N. A regulação da educação na Europa: do Estado educador ao controle social da escola pública. In: BARROSO, J. (Org.). A escola pública: regulação, desregulação, privatização. Porto: Asa, 2003. p. 49-78.

AUTÈS, M. The links between knowledge and politics. Project KnowandPol, 2007. Disponível em: <http://knowandpol.eu/IMG/pdf/lr.tr.autes.eng.pdf>. Acesso em: 8 fev. 2012.

BALL, S. Intellectuals or technicians?: the urgent role of theory in educational studies. British Journal of Educational Studies, Oxford, v. 43, n. 3, p. 255-271, 1995.

BARROSO, J. O século da escola: do mito da reforma à reforma de um mito. In: AMBRÓSIO, T. et al. (Org.). O século da escola: entre a utopia e a burocracia. Lisboa: Asa, 2001. p. 63-94.

BARROSO, J. O Estado e a educação: a regulação transnacional, a regulação nacional e a regulação local. In: BARROSO, J. (Org.). A regulação das políticas públicas de educação: espaços, dinâmicas e atores. Lisboa: Educa, 2006. p. 43-70.

BARROSO, J. Conhecimento, atores e política. Sísifo: Revista de Ciências da Educação, v. 12, p. 37-50, 2010. Disponível em: < http://sisifo.fpce.ul.pt/> Acesso em: 15 out. 2010.

BARROSO J.; CARVALHO, L. Apontamentos sobre os "novos modos de regulação" à luz de estudos sobre as relações entre conhecimento e política. Propuesta Educativa, Buenos Aires, v. 2, n. 36, p. 9-24, 2011.

BOURDIEU, P. Para uma sociologia da ciência. Lisboa: Edições 70, 2004.

BROWN, R.; SCHUBERT, J. Academic knowledge and political power in late capitalist societies. In: BROWN, R.; SCHUBERT, J. (Org.). Knowledge and power in higher education: a reader. New York: Teachers College, 2000. p. 3-13. 
CAMPOS, B.P. As Ciências da Educação em Portugal. Revista Inovação, v. 6, n. 1, p. $11-28,1993$

CAMPOS, B.P. A investigação educacional em Portugal. In: CAMPOS, B.P. (Org.). Investigação educacional em Portugal. Lisboa: Instituto de Inovação Educacional, 1995. p. 59-63.

CARVALHO, L. O Pisa como dispositivo de conhecimento e política. In: CARVALHO, L. (Org.). O espelho do perito: inquéritos internacionais, conhecimento e política em Educação; o caso do Pisa. Lisboa: Fundação Manuel Leão, 2011. p. 11- 40.

COHEN, L.; MANION, L. Research methods in education. New York: Routledge, 1994.

COMMAILLE, J. Sociologie de l'action publique. In: BOUSSAGUET, L.; JACQUOT, S.; RAVINET, P. (Org.). Dictionnaire des politiques publiques. Paris: Science Po., 2006. p. 415-423.

CROZIER, M.; FRIEDBERG, E. L'acteur et le systéme. Paris: Seuil, 1977.

DEMAILLY, L. Les modes de régulation de la société, les instruments de l'action publique et les régimes de connaissance. Project KnowandPol, 2011. Disponível em: <http://www. knowandpol.eu/Les-modes-de-regulation-de-la.html>. Acesso em: 21 jan. 2012.

DESJARDINS, R.; RUBENSON, K. The tension between research of policy and research for policy in an era of transnational educational policy-making: an introduction. In: DESJARDINS, R.; RUBENSON, K. (Org.). Research of vs Research for educational policy - in an era of transnational policy-making. Saarbrucken: Verlag, 2009 , p. 5-43.

FEYERABEND, P. Contra o método. Lisboa: Relógio d'Água, 1993.

FORMOSINHO, J. Especialização docente a administração das escolas: análise das dimensões da especialização docente e problematização da sua articulação com a administração das escolas. Educação, Sociedade E Culturas, Porto, n. 13, p. 7-42, 2000.

FREEMAN, R.; SMITH-MERRY, J.; STURDY, S. Rhizomic regulation: mobilizing knowledge for mental health in Europe. In: BARROSO, J.; CARVALHO, L. (Org.). Knowledge and regulatory processes in health and education policies. Lisboa: Educa, 2012. p. 13-50.

GONÇALVES, M. Mitos e realidades da política científica portuguesa. Revista Crítica de Ciências Sociais, Coimbra, n. 46, p. 47-67, 1996.

HANBERGER, A. Public policy and legitimacy: a historical policy analysis of the interplay of public policy and legitimacy. Policy Sciences, Dordrecht, v. 36, n. 3/4, p. 257-278, 2003. 
HASSENTEUFEL, P. Sociologie politique: l'action publique. Paris: Armand Colin, 2008.

HESSELS, L.K.; VAN LENTE, H. The mixed blessing of mode 2 knowledge production. Science, Technology \& Innovation Studies, v. 6, n. 1, p. 65- 69, 2010.

JOHANNINGMEIER, E.; RICHARDSON, T. Educational research, the national agenda, and educational reform: a history. Charlotte: Information Age, 2008.

KNOWANDPOL Project. Disponível em: <http://www.knowandpol.eu/>. Acesso em: 21 jan. 2008.

LASCOUMES, P.; LE GALES, P. Sociologie de l'action publique. Paris: Armand Colin, 2007.

LIMA, L. Investigação e investigadores em educação: anotações críticas. Sísifo: Revista de Ciências da Educação, v. 12, p. 59-68, out. 2010. Disponível em: <http://sisifo. fpce.ul.pt/> Acesso em: 15 out. 2010.

MANGEZ, E. Economia, política e regimes do conhecimento. In: BARROSO, J.; AFONSO, N. (Org.). Políticas educativas: mobilização de conhecimento e modos de regulação. Lisboa: Fundação Manuel Leão, 2011. p. 191- 222.

MAROY, C.; DEMAILLY, L. Les régulations intermédiaires des systèmes éducatifs en Europe quelles convergences? Recherches Sociologiques, Louvain, v. 35, n. 2, p. 5-24, 2004.

NÓVOA, A. O IIE e a investigação educacional. In: CAMPOS, B.P. (Org.). Investigação e inovação para a qualidade das escolas. Lisboa: Instituto de Inovação Educacional, 1996. p. 89-119.

OZGA, J.; SEDDON, T.; POPKEWITZ, T. Introduction - education research and policy: steering the knowledge-based economy. In: OZGA, J.; SEDDON, T.; POPKEWITZ, T. (Org.). World Yearbook of Education 2006 - education research and policy: steering the knowledge-based economy. London: Routledge, 2006. p. 1-14.

PACHECO, J.A. A reforma do sistema educativo: alguns aspetos da reorganização dos planos curriculares dos ensinos básico e secundário em Portugal e Espanha. Revista Portuguesa de Educação, Braga, v. 4, n. 2, p. 69-83, 1991.

PATRÍCIO, M.F. O Instituto de Inovação Educacional e a organização da comunidade científica-educacional portuguesa. Revista Inovação, v. 2, n. 4, p. 389-402, 1989.

POPKEWITZ, T.; PEREYRA, M. Práticas de reforma na formação de professores em oito países: esboço de uma problemática. In: NÓVOA, A.; POPKEWITZ T. (Org.). Reformas educativas e formação de professores. Lisboa: Educa, 1992. p. 11-41. 
REYNAUD, J.-D. Régulation de controle, régulation autónome, régulation conjoint. In: TERSSAC, G. (Org.). La théorie de la régulation sociale de Jean-Daniel Reynaud. Paris: La Découverte, 2003. p. 103-113.

SILVA, J. A investigação educacional e as políticas educativas: o caso da investigação educacional em Portugal apoiada pelo IIE. 2006. Dissertação (Mestrado) - Instituto Superior de Ciências do Trabalho e da Empresa, Lisboa.

SOUSA SANTOS, B. Um discurso sobre as ciências. Porto: Afrontamento, 1988.

STEINER-KHAMSI, G. Towards a contextualized comparison of European post-bureaucratic states: a commentary. Project KnowandPol, 2008. Disponível em: $<$ http://www. knowandpol.eu/>. Acesso em: 5 set. 2011.

TERSSAC, G. La théorie de la régulation sociale: repères pour un débat. In: TERSSAC, G. (Org.). La théorie de la régulation sociale de Jean-Daniel Reynaud. Paris: La Découverte, 2003. p. 11-33.

VAN ZANTEN, A. Competition and interaction between research knowledge and state knowledge in policy steering in France: national trend and recent effects of decentralization and globalization. In: OZGA J.; SEDDON, T.; POPKEWITZ, T. World Yearbook of Education 2006 - Education research and policy: steering the knowledgebased economy. London: Routledge, 2006. p. 259-268.

VISEU, S. Políticas públicas de ciência e a regulação da investigação educacional: estruturas e redes de investigadores. 2012. Tese (Doutorado) - Instituto de Educação, Universidade de Lisboa, Lisboa. Disponível em: <http://repositorio.ul.pt/bitstream/10451/7064/1/ ulsd_1192_1_td.pdf>. Acesso em: 15 out. 2012.

\section{Fontes}

Lei n. 46/86 de 14 de outubro, Lei de Bases do Sistema Educativo em Portugal.

Decreto-Lei n. 3/87, de 3 de janeiro.

Decreto-Lei n. 435/89, de 18 de dezembro.

Decreto-Lei n. 6/2001, de 18 de janeiro.

Decreto-Lei n. 7/2001, de 18 de janeiro.

O papel do IIE na investigação educacional em Portugal (1993-1999). Lisboa: Instituto de Inovação Educacional.

Plano de atividades do IIE para 1999. 
Modos de regulação institucional da investigação educacional...

Regulamento do Concurso Nacional de projetos de investigação em educação.

Regulamento específico anexo ao Despacho n. 8/IIE/2001.

Relatórios de atividades do IIE de maio de 1993 a outubro 1995, de 1996, 2000 e 2001.

Relatório de execução do sistema de incentivos à qualidade da educação.

Recebido em 20 de junho de 2013.

Aprovado em 18 de fevereiro de 2014. 